\title{
As Estruturas Elementares do Parentesco, de Claude Lévi-Strauss ${ }^{1}$
}

Simone de Beauvoir A análise de Simone de Beauvoir sobre as Estruturas Elementares do Parentesco foi uma das poucas resenhas publicadas à época do lançamento de um dos maiores clássicos da antropologia do século XX. A idéia de traduzi-la partiu inicialmente de Marcos Lanna, quando ainda professor do Departamento de Antropologia da UFPR. O comentário de Mauro W. Barbosa de Almeida que acompanha esse pequeno texto permite apreciar a vigorosa atualidade da reflexão de Simone de Beauvoir, que continua a alimentar um diálogo frutífero entre a etnologia e a filosofia. Os editores agradecem a Angélique Nabet, secretária de redação de Les Temps Modernes, a Sandra Moreira, que intermediou os primeiros contatos com essa revista e a Sylvie Le Bon de Beauvoir, que gentilmente concedeu a autorização final para que pudéssemos disponibilizar aos leitores da Campos este texto inédito no Brasil (N.E.).

Há bastante tempo estava a sociologia francesa adormecida. É necessário saudar o livro de Lévi-Strauss como um evento que marca um brilhante despertar. Os esforços da escola durkheimiana para organizar de uma maneira inteligível os fatos sociais revelaram-se decepcionantes, pois se baseavam em hipóteses metafísicas contestáveis e em postulados históricos não menos duvidosos; como reação, a escola americana pretendeu abster-se de toda especulação: ela se limitou a acumular fatos, sem elucidá-los. Herdeiro da tradição francesa, porém formado de acordo com os métodos americanos, Lévi-Strauss desejou retomar a tentativa de seus mestres, evitando seus defeitos; ele também supôs que as instituições humanas são dotadas de significação; mas procurará a chave desta na humanidade própria daquelas; ele conjura os espectros da metafísica, mas não aceita, por outro lado, que este mundo seja apenas contingência, desordem, absurdo; seu segredo será tentar pensar o dado sem a intervenção de um pensamento que seja estrangeiro a este: no coração da realidade ele descobrirá o espírito que a habita. Assim ele nos reconstitui a imagem de um universo que não tem a necessidade de refletir o céu para ser um universo humano. 
Não me pertence a tarefa de criticar - e sim a de apreciar - esta obra especializada: mas não é somente aos especialistas que ela se dirige. Que o leitor que abra o volume por acaso não se deixe intimidar pela misteriosa complexidade dos diagramas e gráficos; na verdade, quando o autor discute minuciosamente o sistema matrimonial dos Murngin ou dos Katchin, é o mistério da sociedade como um todo, o mistério do homem, que ele se esforça por descobrir.

O problema ao qual ele se dedica é o mais fascinante e o mais desconcertante de todos os que têm mobilizado etnógrafos e sociólogos: trata-se do enigma colocado pela proibição do incesto. A importância deste fato e sua obscuridade resultam da situação única que ele ocupa no conjunto dos fatos humanos. Estes se dividem em duas categorias: os fatos da natureza e os fatos da cultura; certamente nenhuma análise permite descobrir entre eles o ponto de passagem. Mas eles se distinguem sob um critério seguro: os primeiros são universais; os segundos obedecem a normas. A proibição do incesto é o único fenômeno que escapa dessa classificação: pois ela aparece em todas as sociedades, sem exceção, e ao mesmo tempo é uma regra. As diferentes interpretações tentadas até então se esforçaram todas para mascarar essa ambigüidade. Alguns pensadores evocaram os dois aspectos - natural e cultural - da lei; mas eles apenas estabeleceram entre eles uma relação intrínseca; supuseram que um interesse biológico teria engendrado a interdição social; outros viram na exogamia um fato puramente natural: ela seria ditada por um instinto; outros enfim, dentre os quais Durkheim, consideraram-na exclusivamente um fenômeno cultural. Esses três tipos de explicação têm conduzido a impossibilidades e contradições. Na verdade, se a proibição do incesto é de tão grande interesse, é porque ela representa o momento mesmo da passagem da natureza para a cultura. "É o processo pelo qual a natureza ultrapassa a ela mesma". Essa singularidade decorre do caráter particular da sexualidade mesma: é normal que a dobradiça entre natureza e cultura se encontre no terreno da vida sexual, pois esta, extraída da biologia, coloca imediatamente outrem em jogo; no fenômeno da aliança se desenvolve essa dualidade: pois enquanto o parentesco é dado, a natureza impõe a aliança, mas não a determina. Podemos extrair daqui a maneira pela qual o homem, assumindo sua condição natural, define sua humanidade. Pela proibição do incesto se expressam e se realizam as estruturas fundamentais sobre as quais se funda a sociedade humana como tal.

Primeiramente a exogamia manifesta que não haveria sociedade sem o reconhecimento de uma Regra. Contrariamente aos mitos e às inverdades liberais, a intervenção não está somente relacionada a alguns regimes econômicos: ela é tão original quanto a humanidade mesma. A distribuição dos valores entre os membros da coletividade sempre foi e será um fenômeno cultural; porém - como o alimento ao qual ela é estreitamente associada -, a mulher é um produto escasso e essencial à vida do grupo: em muitas civilizações primitivas, o solteiro é econômica e socialmente um pária; o primeiro cuidado da coletividade será assim impedir que se estabeleça um monopólio de mulheres. Este é o sentido profundo da proibição do incesto; afirma-se que não é sobre a base de sua repartição natural que as mulheres devem receber um uso social; se ao homem se impede escolher seus aliados entre os seus parentes, se "congelamos" as mulheres no seio da família, é porque a distribuição se faz sobre o controle do grupo e não em regime privado. A despeito de seu aspecto negativo, a Regra tem na verdade um sentido positivo; a interdição implica imediatamente uma organização: pois para renunciar a seus parentes, é necessário que o indivíduo seja 
assegurado de que a renúncia simétrica de um outro lhe conceda aliados; ou seja, a regra é a afirmação de uma reciprocidade; a reciprocidade é a maneira imediata de integrar a oposição entre mim e outrem: sem uma tal integração, a sociedade não existiria. Porém, tal relação não existiria se permanecesse abstrata; sua tradução concreta é a troca: a transferência de valores de um indivíduo a outro os transforma em parceiros; somente sob essa condição pode se estabelecer um "mitsein" humano. A característica fundamental destas estruturas se revela claramente no estudo da psicologia infantil: a criança faz o aprendizado de si mesma e do mundo aprendendo a aceitar a arbitragem de um outro, quer dizer, a Regra, que a faz descobrir a reciprocidade, descoberta à qual ela reage imediatamente pelo dom e pela exigência. Essa noção de troca - cuja importância Mauss já havia estabelecido no seu ensaio sobre o dom, e que envolve as noções de regra e de reciprocidade - nos fornece a chave do mistério da exogamia: proibir uma mulher aos membros de um dado grupo é colocá-la imediatamente à disposição de outro homem; a proibição se duplica em obrigação: aquela de dar sua filha, sua mulher, a outro homem; a parenta que se rejeita, se oferece; o fato sexual, ao invés de fechar-se sobre si, abre um vasto sistema de comunicação. A proibição do incesto se confunde com a instauração da ordem humana. Os homens em toda parte procuraram estabelecer um regime matrimonial tal que a mulher faça parte dos dons pelos quais se expressa a relação de cada um ao outro e se afirma a existência social.

Uma observação extremamente importante impõe-se aqui: não é entre os homens e as mulheres que aparecem as relações de reciprocidade e de troca; elas se estabelecem por meio das mulheres, entre os homens; existe e sempre existiu entre os sexos uma profunda assimetria e o "Reino das mulheres" é um mito superado; qualquer que seja o modo de descendência [N.T.: filiation no original], quer os filhos sejam incluídos no grupo do pai ou naquele da mãe, as mulheres pertencem aos machos [N.T.: males no original] e fazem parte do conjunto de prestações que eles se consentem. Todos os sistemas matrimoniais implicam que as mulheres sejam dadas por certos machos a outros machos.

Há um caso onde a relação entre o casamento e a troca aparece claramente: é o das organizações dualistas; estas apresentam analogias tão fortes entre si que se tentou às vezes Ihes dar uma origem única: segundo LéviStrauss, sua convergência se explica pela identidade de seu caráter funcional. Não é o sistema dualista que faz nascer a reciprocidade: ele antes a exprime de uma forma concreta. É esta mesma perspectiva que permitirá explicar as formas de sociedade mais complexas: elas não são o resultado de acasos históricos e geográficos; todas elas manifestam uma mesma e profunda intenção: a de impedir o grupo de se fechar em si mesmo e de mantê-lo diante de outros grupos com os quais a troca seja possível.

O autor buscará a confirmação dessas idéias em uma minuciosa análise de realidades sociais dadas; é esse estudo que constitui a parte mais importante de seu trabalho. Não seria questão aqui de repassar os complicados meandros; tentarei somente indicar o método, já que é na sua aplicação metódica que uma hipótese manifesta sua fecundidade.

A forma do casamento que fornece o verdadeiro experimentum crucis do estudo das proibições matrimoniais é o casamento entre primos cruzados. Em um grande número de sociedades primitivas o casamento é proibido entre primos paralelos - aqueles provenientes de dois irmãos ou duas irmãs - e recomendado entre primos cruzados - isto é, advindos de um irmão e uma irmã; o extremo interesse desse costume provém do 
fato de que graus de parentesco biologicamente equivalentes são considerados de um ponto de vista social como radicalmente dessemelhantes: torna-se patente que não é a natureza quem dita suas leis à sociedade; compreendendo-se a origem dessa assimetria tem-se a explicação da proibição do incesto. $\mathrm{O}$ casamento entre primos cruzados implica uma organização dualista da coletividade: eles distribuem-se de fato como se pertencessem a duas metades diferentes; mas não se deve crer que seja esta a divisão que define as regras de exogamia; os primitivos não começam estabelecendo classes: a classe é um elemento analítico, como o conceito; o homem pensa antes que o lógico apreenda o pensamento enquanto forma; assim a sociedade se organiza antes de definir os elementos separados que essa organização trará à tona; lá onde são encontradas as classes - e isso não é por toda parte - elas são menos um grupo de indivíduos concebidos em extensão que um sistema de posição, no qual somente a estrutura é constante e onde os indivíduos podem se deslocar, desde que as relações sejam respeitadas. O princípio da reciprocidade age de duas maneiras complementares: constituindo classes que delimitam em extensão os cônjuges ou determinando uma relação que permita dizer se um indivíduo é ou não um cônjuge possível: no caso dos primos cruzados, esses dois aspectos do princípio se recobrem; mas não é seu pertencimento a dois grupos diferentes que os destina a se aliar entre si; ao contrário, a razão de ser do sistema que os opõe é a possibilidade de uma troca. As mulheres aparecem imediatamente como destinadas a serem trocadas e esta perspectiva cria imediatamente uma oposição entre dois tipos de mulheres: a irmã e a filha que devem ser cedidas e a esposa que é adquirida, ou seja, a parente e a aliada. Não se trata aqui, como pensava Frazer, da solução de um problema econômico: os processos econômicos não são isoláveis; é um ato de consciência primitivo e indivisível que faz apreender a filha e a irmã como um valor ofertável e a filha e a irmã de outrem como um valor exigível. Antes mesmo que a coisa a trocar se apresente, a relação de troca já está dada: antes do nascimento de sua filha, o pai sabe que deverá entregá-la ao homem - ou ao filho do homem - de quem recebeu a irmã em casamento. Os primos cruzados são provenientes de famílias que se encontram em posições antagônicas, em um desequilibro dinâmico que somente a aliança pode resolver; ao contrário, duas irmãs ou dois irmãos, pertencentes ao mesmo grupo, têm entre eles uma relação estática e seus filhos serão considerados como fazendo parte de um mesmo conjunto; eles não portam um em relação ao outro o sinal [N.T.: signe no original] da alteridade, necessário ao estabelecimento das alianças.

Porém, se nos limitarmos a considerar a troca sob essa forma restrita - ou seja, na medida que ela estabelece uma reciprocidade entre um certo número de pares de unidades trocadoras, classes, seções ou sub-seções - percebemos que ela não permite dar conta da integralidade dos fatos. É o que se evidencia, por exemplo, na análise dos fatos australianos. É sob sua forma generalizada que a idéia de troca pode servir de chave para o estudo de todas as sociedades. A troca generalizada é aquela que estabelece relações de reciprocidade entre um número qualquer de parceiros [N.T.: desde que maior do que dois]: assim, se um homem do grupo $A$ esposa necessariamente uma mulher $B$, ao passo que um homem $B$ esposa uma mulher $C$, o homem $C$ uma mulher $D$, e o homem $D$ uma mulher $A$, está-se diante de um sistema de troca generalizada; é o que se produz, entre outros, no caso em que o casamento é matrilateral, ou seja, o homem deve desposar a filha de seu tio materno. Essa regra estabelece o desenvolvimento de um ciclo aberto no qual cada indivíduo deve ter confiança: quando o grupo $A$ cede uma mulher ao $B$, trata-se de uma especulação de longo prazo, pois ele deve contar que $B$ cederá uma mulher a $C$, e deste $a \mathrm{D}$, e este a $A$; tal cálculo comporta riscos e é por isso que à troca generalizada 
freqüentemente se superpõem novas fórmulas de aliança, como o matrimônio por compra, que permite integrar fatores irracionais, sem destruir o sistema.

A aplicação desses princípios diretores permite a Lévi-Strauss depreender a significação de regimes matrimoniais que pareciam até então contingentes e ininteligíveis. A conclusão destas análises que nos transportam à Austrália, à China, às Índias e às Américas é que existem dois tipos essenciais de exogamia. À troca direta corresponde o casamento bilateral, o indivíduo podendo desposar a filha de seu tio materno ou de sua tia paterna; à troca indireta (ou generalizada) corresponde o casamento matrilateral que autoriza a aliança exclusivamente com a filha do tio materno [N.T.: a autora não considera que Lévi-Strauss também toma o casamento com a prima cruzada patrilateral como um modo de troca generalizada]. O primeiro sistema só é possível nos regimes desarmônicos, ou seja, onde a residência e a filiação seguem um a linha paterna e o outro a linha materna; o segundo aparece nos regimes harmônicos, onde residência e filiação seguem a mesma linha; o primeiro possui uma grande fecundidade em relação ao número de sistemas que é capaz de fundar, mas sua fecundidade funcional é relativamente fraca; o segundo é, ao contrário, um princípio regulador fecundo que conduz a uma maior solidariedade orgânica no seio do grupo; no caso da troca restrita, é a inclusão ou a exclusão dentro ou fora da classe que faz o papel principal; no caso da troca indireta, o grau de parentesco, ou seja, a natureza da relação, tem uma importância preponderante; os sistemas desarmônicos têm assim evoluído na direção de organizações de classes matrimoniais, enquanto o contrário é produzido nos sistemas harmônicos. Estes constituem um ciclo aberto, longo, aqueles um ciclo curto; o casamento bilateral é uma operação mais segura; mas o casamento matrilateral oferece virtualidades inesgotáveis, a extensão do ciclo estando na razão inversa de sua segurança. É por isso que um fator alógeno se sobrepõe quase sempre às formas simples da troca generalizada; entre grupos que se lançam nessa grande aventura sociológica, nenhum é liberado inteiramente da inquietude engendrada pelos riscos do sistema, e eles mantêm um certo coeficiente ou mesmo um símbolo de patrilateralidade. Nenhum sistema é puro: ele é simultaneamente simples e coerente, porém cercado por outros sistemas.

Resta acrescentar que a estrutura de troca não é solidária da prescrição de um cônjuge preferencial; entre outras, a substituição do direito sobre a prima pela compra da mulher permite à troca se desembaraçar de suas formas elementares. Mas quer seja indireta ou direta, global ou específica, concreta ou simbólica, é sempre a troca que nós encontramos na base das instituições matrimoniais. Vê-se então se confirmar a idéia de que a exogamia visa assegurar a circulação total e contínua das mulheres e das filhas; seu valor não é negativo, mas positivo: não é que haja um perigo biológico no casamento consangüíneo, mas um benefício social resulta do casamento exogâmico. A proibição do incesto é por excelência a lei do dom: é a instauração da cultura no seio da natureza.

“Todo casamento é um encontro dramático entre a natureza e a cultura, entre a aliança e o parentesco... Já que se deve ceder à natureza para que a espécie se perpetue e com ela a aliança social, é necessário ao menos negá-la ao mesmo tempo em que acedemos a ela". Em um sentido, todo casamento é um incesto social, já que o marido absorve em si algum bem ao invés de desviá-lo na direção de outrem [N.T.: no original, s'échapper vers autrui]; ao menos a sociedade exige que no centro desse ato egoísta a comunicação com o grupo seja mantida: é por isso que, ainda que mulher seja outra coisa além de um signo, ela é todavia, como a palavra, uma coisa que se troca. 
A relação do homem com a mulher é também fundamentalmente uma relação com outros homens - com outras mulheres. Os enamorados nunca estão sozinhos no mundo. $\mathrm{O}$ evento mais íntimo para cada um, o ato sexual é também um evento público: ele coloca em questão, ao mesmo tempo, o indivíduo e a sociedade inteira; é daí que vem seu caráter dramático; aqueles que se escandalizam com o ardente interesse que lhe dão os homens hoje em dia demonstram grande ignorância: a extrema importância conferida aos tabus sexuais nos mostra que esta preocupação é velha como o mundo; e ela está longe de ser supérflua, já que, pela maneira como assume sua sexualidade, o homem define sua humanidade.

Certamente essa escolha que ele faz não é fruto de uma deliberação refletida. Mas o primeiro mérito do estudo de Lévi-Strauss é precisamente o de recusar o velho dilema: ou os fatos humanos são intencionais ou não possuem significação. O autor os define como estruturas nas quais o todo precede as partes e cujo princípio regulador possui um valor racional mesmo quando não seja racionalmente concebido. De onde provêm estrutura e princípio? Lévi-Strauss não se permite aventurar sobre o terreno filosófico, não se separa jamais de uma rigorosa objetividade científica; mas seu pensamento se inscreve evidentemente na grande corrente humanista que considera a existência humana como contendo em si sua própria razão. Não se poderia ler suas conclusões sem se lembrar das palavras do jovem Marx: "A relação do homem com a mulher..."

Entretanto o livro não desperta apenas ressonâncias marxistas; ele me pareceu muitas vezes reconciliar de modo feliz Engels e Hegel: pois o homem nos aparece originalmente como uma antiphysis; e o que realiza sua intervenção é a posição concreta de um eu face a um outro eu, sem o qual o primeiro não saberia se definir. Também fui singularmente surpreendida pela concordância de algumas descrições com as teses sustentadas pelo existencialismo: a existência, ao se colocar, coloca suas leis, em um único movimento; ela não obedece a nenhuma necessidade interior, entretanto escapa à contingência por assumir as condições de seu brotar. Se a proibição do incesto é universal e normativa ao mesmo tempo, é porque ela traduz uma atitude original do existente: ser homem é se escolher como homem, definindo suas possibilidades sobre a base de uma relação recíproca com o outro; a presença do outro nada tem de acidental: a exogamia, bem longe de se limitar a registrála, ao contrário, a constitui; através dela se expressa e se realiza a transcendência do homem; ela é a recusa da imanência, a exigência de ultrapassá-la; aquilo que os regimes matrimoniais asseguram ao homem, pela comunicação e pela troca, é um horizonte em direção ao qual ele possa se projetar; sob sua aparência barroca, eles Ihe asseguram um além-humano (N.T.: no original, au-delá humain).

Mas seria trair um livro tão imparcial pretender fechá-lo dentro de um sistema de interpretação: sua fecundidade está precisamente em convidar cada um a repensá-lo a sua maneira. É por isso também que nenhuma resenha lhe faria justiça; uma obra que nos apresenta os fatos, que instaura um método, e que sugere especulações, merece que cada um renove a descoberta: é preciso lê-la.

Tradução: Marcos P. D. Lanna (UFSCar) e Aline Fonseca lubel (PPGAS/UFPR). 


\section{NOTAS}

1 Texto original: Simone de Beauvoir. 1949. "Les Structures Élémentaires de la Parenté, par Claude Lévi-Strauss". Les Temps Modernes 7(49): 943-9 (October). 
190 